\title{
DEVELOPMENT OF A GEOMORPHOLOGY-BASED HYDROLOGICAL MODEL FOR LARGE CATCHMENTS
}

\author{
Dawen YANG ${ }^{1}$, Srikantha HERATH ${ }^{2}$, Katumi MUSIAKE ${ }^{3}$ \\ ${ }^{1}$ Student Member of JSCE, M. Eng., Institute of Industrial Science, University of Tokyo(7-22-1 \\ Roppongi, Minato-ku, Tokyo 160, JAPAN) \\ ${ }^{2}$ Member of JSCE, Dr. of Eng., Professor, Institute of Industrial Science, University of Tokyo(7-22-1 \\ Roppongi, Minato-ku, Tokyo 160, JAPAN) \\ ${ }^{3}$ Member of JSCE, Dr. of Eng., Professor, Institute of Industrial Science, University of Tokyo(7-22-1 \\ Roppongi, Minato-ku, Tokyo 160, JAPAN)
}

\begin{abstract}
The grid-based distributed hydrological models are powerful tools for hydrological modeling due to the representation of the spatial varibility and the physically-based process descriptions. However, because of the large computational demands this kind of models are not suitable for long term simulations in large catchments. Here, an alternative distributed hydrological model is proposed, which is based on the catchment geomorphology area function and width function. In this model, the catchment is discretized into a number of flow intervals along the flow direction. Each flow interval is represented as a series of hillslope elements. A hillslope response model and the kinematic wave model are used to simulate the runoff generation and river routing. The applicability of the model for the simulation of multiple catchments is discussed in the paper.
\end{abstract}

Key Words: distributed hydrological model, geomorphology, area function, width function

\section{INTRODUCTION}

The distributed hydrological modeling is necessary when the spatial distribution of hydrologic variables are important. In general, for distributed hydrologic modeling, the catchments are discretized into a number of small grids. However, large computational demands and model complexities are a deterrent to the use of distributed hydrologic models in vcry large catchments, such as for regional water resources planning. Therefore development of computationally fast and easy to implement models is an important task. The catchment geomorphologic area function (and width function) used by Yang et al. $(1997)^{1)}$ provides a possibility to quantitatively describe the catchment heterogeneity. The area function shows the aggregating pattern of the catchment. Naden (1992) ${ }^{2)}$ described the rainfall and soil properties in a hydrological model coupled with width function. Yang et al. $(1997)^{3)}$ used area function to describe the rainfall distribution for modeling flood by coupling with the tank model. Here we present a method, which employs the geomorphologic area function and width function to reduce the catchment lateral dimension from two to one. The methodology makes it possible to reduce the 2-dimensional spatial data to 1-dimensional distribution functions of characteristics with respect to flow distance from the catchment outlet, which improves the hydrological modeling efficiency while retaining the spatial heterogeneity information. This methodology was used for simulating floods (Yang et al., 1997) ${ }^{4}$. The main objective of this paper is to investigate the applicability of the method for long term simulation in large catchments.

\section{MODEL DESCRIPTION}

\section{(1) Discretization of catchment spatial heterogeneity}

When the river network is generated using flow accumulation method, the flow direction in each cell is determined according to the steepest descent direction. Following the flow direction, the flow distance of each cell from catchment outlet can be calculated. The area function can be 


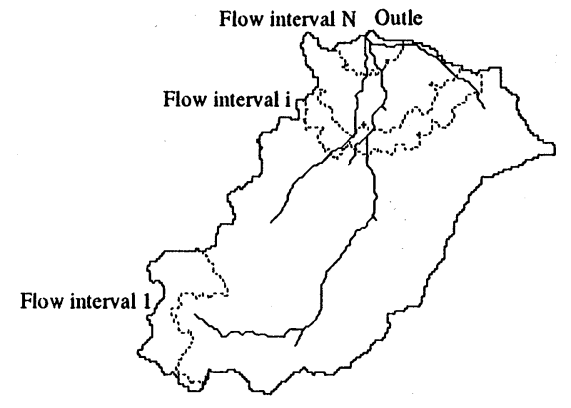

Fig. 1 Flow interval

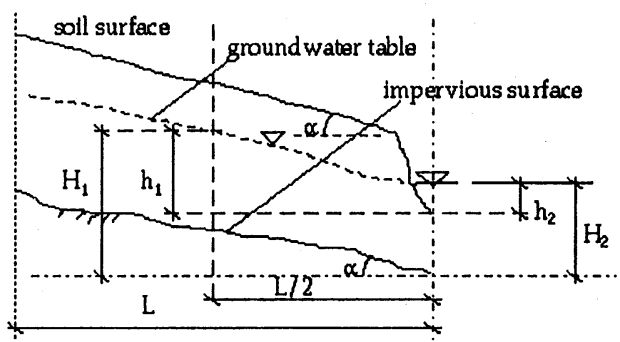

Fig. 2 Hillslope element

uniquely derived from this method. Considering any flow interval $\Delta x$ at distance $x$, the catchment area accumulated in this interval is given by the area function. For hydrological modeling, the catchment is divided into a number of flow intervals (Fig.1). Each flow interval is represented using a number of hillslope elements. The number of hillslope elements depends on the number of streams within the same flow interval. The spatially distributed parameters of the catchment, such as rainfall, elevation and hillslope angle, are averaged for each flow interval. Similar to area function, the spatial distribution of catchment parameters are given by distribution functions.

\section{(2) Hillslope response model}

The hillslope element is assumed as a rectangular inclined plane with width of flow interval $\Delta x$, length of $L$ and angle $\alpha$. The bed rock slope is assumed to be parallel to the surface. The hillslopes are located in both sides of the river symmetrically (Fig.2). The hydrological processes on hillslope include interception, evapotranspiration, infiltration, overland flow, unsaturated soil water and groundwater flow. In the hillslope model, the vertical plane is divided into several layers, including canopy, soil surface, a number of soil zones (parallel to the surface) and shallow groundwater layer. For each layer, storage-based models are used. The macropores in top soil is represented using an anisotropy ratio, defined as

$$
a_{r}=K_{s p} / K_{s n}>1
$$

where, $a_{r}$ is the anisotropic ratio, $K_{s p}$ and $K_{s n}$ are the saturated hydraulic conductivities in the directions normal $(n)$ and parallel $(p)$ to the slope respectively $(\mathrm{mm} / \mathrm{h})$. The exponential assumption is adopted here for representing the decrease of hydraulic conductivity with depth, given as

$$
K_{s}(n)=K_{0} e^{-f n}
$$

where, $K_{s}(n)$ is the saturated hydraulic conductivity at depth $n(\mathrm{~mm} / \mathrm{h}), n$ is the distance taken positive in downward direction normal to surface $(\mathrm{m}), K_{0}$ is the saturated conductivity at surface $(\mathrm{mm} / \mathrm{h}), f$ is a parameter $(1 / \mathrm{m})$.

\section{a) Interception and evapotranspiration}

The interception capacity depends on the vegetation coverage and the leaf-area-index. Actual interception is determined by the precipitation amount and the deficit of the canopy water storage. Interception capacity is given by

$$
S_{c_{0}}(t)=I_{0} K_{v} L A I(t)
$$

The deficit of canopy water storage is

$$
S_{c_{d}}(t)=S_{c_{0}}-S_{c}(t)
$$

where, $S_{c_{o}}$ is the interception capacity $(\mathrm{mm}) ; I_{0}$ is the maximum interception ability of the vegetation in a year $(\mathrm{mm}) ; K_{v}$ is the vegetation coverage; $L A I$ is the leaf-area-index, where the maximum is $1 ; S_{c_{d}}(t)$ is the deficit of canopy water storage $(\mathrm{mm}) ; S_{c}(t)$ is the canopy water storage at time $t(\mathrm{~mm})$.

The potential evaporation is estimated using radiation-based method because of the available data. Actual evapotraspiration is calculated as evaporation from canopy water storage, transpirtation from root zone, evaporation from surface storage and evaporation from soil surface. The evaporation from soil suface is estimated as a function of average soil moisture content in the first zone. The evapotraspiration is assumed take place only during the daytime 12 hours. The daily potential evaporation is divided by 12 hours to convert it to hourly potential evaporation. Actual evaporation rate from canopy is given by

$$
E_{\text {canopy }}(t) \Delta t=\left\{\begin{array}{cc}
E_{p} \Delta t & S_{c}(t) \geq E_{p} \Delta t \\
S_{c}(t) & S_{c}(t)<E_{p} \Delta t
\end{array}\right.
$$

where, $E_{\text {canopy }}$ is the actual evaporation rate from canopy storage $(\mathrm{mm} / \mathrm{h}) ; E_{p}$ is the potential evaporation rate $(\mathrm{mm} / \mathrm{h}) ; \Delta t$ is the time interval $(\mathrm{h})$. The vegetation traspiration rate from each soil zone is written as

$$
\begin{aligned}
E_{t r_{i}}(t, i)= & \left\{K_{c} E_{p}-E_{\text {canopy }}(t)\right\} * \\
& K_{v} f_{1}\left(z_{i}\right) f_{2}\left(\theta_{i}\right) L A I(t)
\end{aligned}
$$


where, $E_{t r_{i}}(t, i)$ is the transpiration rate $(\mathrm{mm} / \mathrm{h})$ from zone $i$ at time $t ; K_{c}$ is crop coefficient; $f_{1}$ is the root distribution function; $f_{2}\left(\theta_{i}\right)$ is soil moisture function; $\theta_{i}$ is the soil moisture content of layer $i$. The actual evaporation rate from soil water storage is given by

$$
E_{\text {surface }}(t) \Delta t=\left\{\begin{array}{l}
E_{p}\left(1-K_{v}\right) \Delta t \\
S_{s}(t) \geq E_{p}\left(1-K_{v}\right) \Delta t \\
S_{s}(t), \\
S_{s}(t)<E_{p}\left(1-K_{v}\right) \Delta t .
\end{array}\right.
$$

where, $E_{\text {surface }}$ is the evaporation rate from surface water $(\mathrm{mm} / \mathrm{h}) ; S_{s}(t)$ is the surface water storage at time $t(\mathrm{~mm})$. The evaporation rate from soil surface is given by

$$
E_{s}(t) \Delta t=\left\{E_{p}\left(1-K_{v}\right)-E_{\text {surface }}(t)\right\} f_{2}(\theta)
$$

where $E_{s}(t)$ is the evaporation rate from soil surface $(\mathrm{mm} / \mathrm{h})$.

\section{b) Surface runoff and infiltration}

The mass balance for the surface storage is given by

$$
\begin{aligned}
\Delta S_{s}(t+\Delta t)= & P_{n}(t)+M_{s}(t)-q_{s}(t) \\
& -f_{\text {in }}(t)-E_{\text {surface }}(t)
\end{aligned}
$$

where, $\Delta S_{s}(t+\Delta t)$ is the change of surface water storage at time $t$ during time duration $\Delta t(\mathrm{~mm})$; $P_{n}(t)$ is net rainfall intensity at time $t(\mathrm{~mm} / \mathrm{h})$; $f_{\text {in }}(t)$ is the infiltration rate at time $t(\mathrm{~mm} / \mathrm{h})$, given by

$$
f_{i n}(t)=\left\{\begin{array}{cc}
P_{n}(t) & P_{n}(t)<K_{0} \\
K_{0} & P_{n}(t) \geq K_{0}
\end{array}\right.
$$

$q_{s}(t)$ is the surface runoff $(\mathrm{mm} / \mathrm{h})$, calculated by

$$
q_{s}(t) \Delta t=\left\{\begin{array}{cc}
S(t)-S_{\max } & S(t)>S_{\max } \\
0 & S(t) \leq S_{\max }
\end{array}\right.
$$

in which, $S(t)$ is the surface water storage at time $t(\mathrm{~mm}) ; S_{\max }$ is the maximum surface storage $(\mathrm{mm})$.

\section{c) Unsaturated zone (multiple layers)}

The top unsaturated soil is divided into multiple layers, the mass balance for layer $i$ is given by

$$
\begin{aligned}
\Delta S_{s u b_{i}}(t+\Delta t) / \Delta t= & f_{i-1}(t)-f_{i}(t) \\
& -E_{t r_{i}}(t)-E_{s_{i}}(t)
\end{aligned}
$$

where, $\Delta S_{s u b_{i}}$ is the change of water storage in layer $i$ at time $t$ during time interval $\Delta t(\mathrm{~mm})$; $f_{i}(t)$ is the recharge rate $(\mathrm{mm} / \mathrm{h})$ from layer $i$ to layer $i+1 ; f_{0}(t)=f_{i n}(t) . f_{i}(t)(i>0)$ is given by

$$
f_{i}(t)=\left\{\begin{array}{l}
K\left(\theta_{i}\right) \frac{\partial(z+\psi)}{\partial z} \approx K\left(\theta_{i}\right) \\
\theta_{i}>\theta_{f} \text { or } \theta_{i+1} \leq \theta_{i} \\
0, \quad \theta_{i} \leq \theta_{f} \text { and } \theta_{i+1}>\theta_{i}, z_{i+1}>z_{i} .
\end{array}\right.
$$

in which, $\theta_{i}$ is the soil moisture content in layer $i$; $K\left(\theta_{i}\right)$ is the hydraulic conductivity $(\mathrm{mm} / \mathrm{h})$.

\section{d) Saturated zone and exchange with the} river

The basic equations used for the saturated zone are mass balance and Darcy's law. The mass balance is give by

$$
\begin{aligned}
\Delta S_{G}(t+\Delta t) / \Delta t= & \operatorname{reach}(t)-L(t) \\
& -q_{G}(t) \frac{1000}{A}
\end{aligned}
$$

where, $\Delta S_{G}(t+\Delta t)$ is the change of groundwater storage (unconfined aquifer) $(\mathrm{mm}) ; \operatorname{rech}(t)$ is the recharge rate from upper unsaturated zone $(\mathrm{mm} / \mathrm{h}) ; L(t)$ is the leakage to deep aquifer $(\mathrm{mm} / \mathrm{h}) ; A$ is the plane area of hillslope element per unit width $\left(\mathrm{m}^{2} / \mathrm{m}\right) ; q_{G}(t)$ is the discharge to the river per unit width $\left(\mathrm{m}^{3} / \mathrm{h}\right.$ per meter $)$, calculated as

$$
q_{G}(t)=K_{G} \frac{H_{1}-H_{2}}{L / 2} \frac{h_{1}+h_{2}}{2}
$$

where, $K_{G}$ is the hydraulic conductivity of unconfined aquifer.

\section{(3) River routing}

The kinematic wave model given by the continuity and momentum equations is used for river routing and solved using explicit finite difference method.

$$
\frac{\partial Q}{\partial x}+\frac{\partial A}{\partial t}=q_{L}, \quad q_{L}=q_{s}+q_{G}
$$

Momentum equation is given by Manning's equation

$$
Q=\frac{S_{0}^{1 / 2}}{n P^{2 / 3}} A^{5 / 3}
$$

where, $x$ is distance along the longitudinal axis of the river $(\mathrm{m}) ; t$ is time (s); $A$ is cross-sectional area $\left(\mathrm{m}^{2}\right) ; Q$ is discharge at $x\left(\mathrm{~m}^{3} / \mathrm{s}\right) ; q_{L}$ is lateral inflow ( $\mathrm{m}^{3} / \mathrm{s}$ per meter); $S_{0}$ is the river bed slope; $n$ is Manning's roughness; $P$ is wetting perimeter $(\mathrm{m})$.

\section{INVESTIGATION OF MODEL PERFORMANCE}

\section{(1) Study Area}

The Karasu River, which is located in north of Tokyo, is selected for this study (Fig.3). Total catchment area is $1220.8 \mathrm{~km}^{2}$ at the dischargegauge $\mathrm{D}$ and $80 \%$ of the area is mountainous. It contains two main sub-catchments with areas of $536.3 \mathrm{~km}^{2}$ (at D-1) and $555.2 \mathrm{~km}^{2}$ (at D-2). There are 6 raingauges within or near the catchment . Three years data sets (1992-1994) of daily discharge and hourly rainfall are available. The daily temperature and sunshine duration data at 


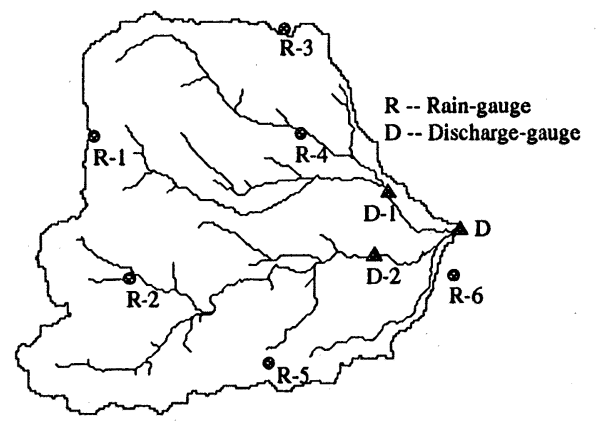

Fig. 3 Study area

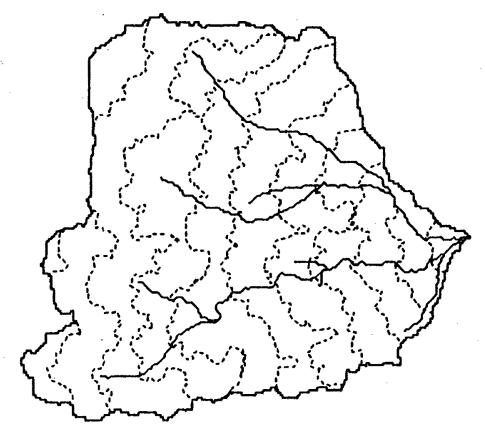

Fig. 4 Flow distance contours for whole catchment

two gauges are used to estimate the potential evaporation. The first year data is used to initialize the initial condition by repeating the simulation twice and calibrate the model parameters. The calibrated parameters are the saturated hydraulic conductivity of the surface soil (with value of $80.0 \mathrm{~mm} / \mathrm{h}$ ) and the hydraulic conductivity of groundwater (with value of $5.0 \mathrm{~mm} / \mathrm{h}$ for subcatchment D-1 and $1.0 \mathrm{~mm} / \mathrm{h}$ for sub-catchment D-2). The saturated hydraulic conductivities of the top zone soil are decreasing according to equation 2. The other soil parameters are used as same as Kanto loam. The simulation has been carried in this catchment from year 1993 to 1994 .

\section{(2) Modeling considerations}

There are two basic considerations investigating the model performance. a) Effect of flow interval length; b) Effect of averaging of hillslope parameters. The simulations are carried out first, as a system of independent catchments linked by the river network, and then, treating the whole area as a single catchment. In order to investigate the above problems, single land cover (forest) and a single soil type (Kanto loam) is used for whole catchment in the analysis. Fig.4 shows the flow distance contours for whole area treated as a single catchment. Fig.5 gives the flow distance

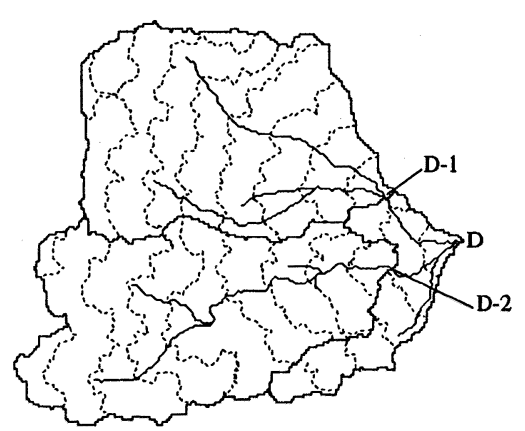

Fig. 5 Flow distance contours for each sub-catchment

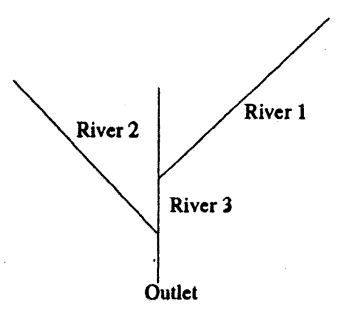

Fig. 6 Network routing

contours for each sub-catchment from outlet of each catchment.

\section{(3) Effect of flow interval length}

The whole catchment is divided into three sub-catchments: sub-catchment 1 (upper part of discharge-gauge D-1), sub-catchment 2 (upper part of discharge-gauge D-2) and sub-catchment 3 (the residual part). The hillslope responses of each sub-catchment are simulated independently. The river network of each sub-catchment is simplified using the main channels of each subcatchment. The river routing is solved using network routing (Fig.6). The flow intervals are determined automatically according to the main channel links, and flow interval lengths are made to be less than $600 \mathrm{~m}$ or $300 \mathrm{~m}$ for two simulations respectively. Figs.7 and 8 show the comparisons of simulated daily hydrographs with the observed ones at discharge-gauge D-1 and D-2 respectively for the case that flow interval length less than 600 m. Table 1 shows the simulation error and CPU time (WindowsNT $433 \mathrm{MHz}$ computer) for the two simulations for a period of two years. The simulation error is calculated as

$$
\text { error }=\frac{\Sigma \sqrt{\left(Q_{0}-Q_{s}\right)^{2}}}{N \bar{Q}_{0}}
$$

where $Q_{0}$ is the observed discharge; $Q_{s}$ is the simulated discharge; $N$ is the total number of the 


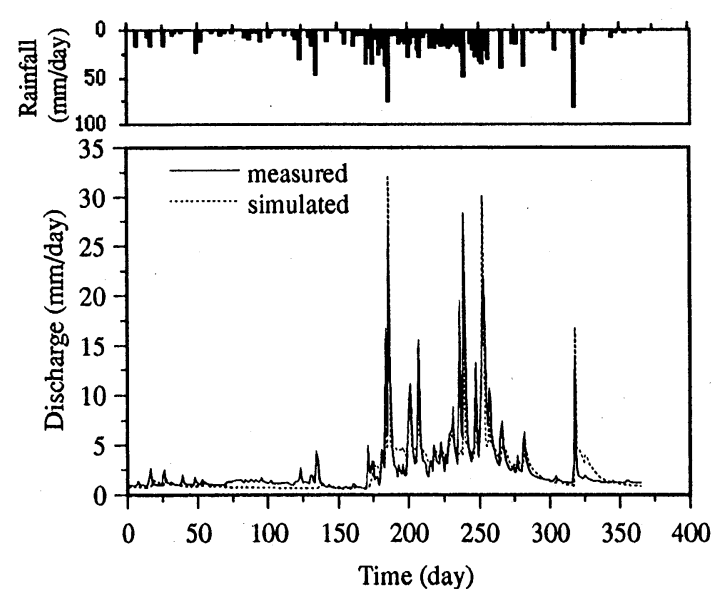

Fig. 7 Daily hydrographs at D-1 for case of flow interval length less than $600 \mathrm{~m}$ for year 1993

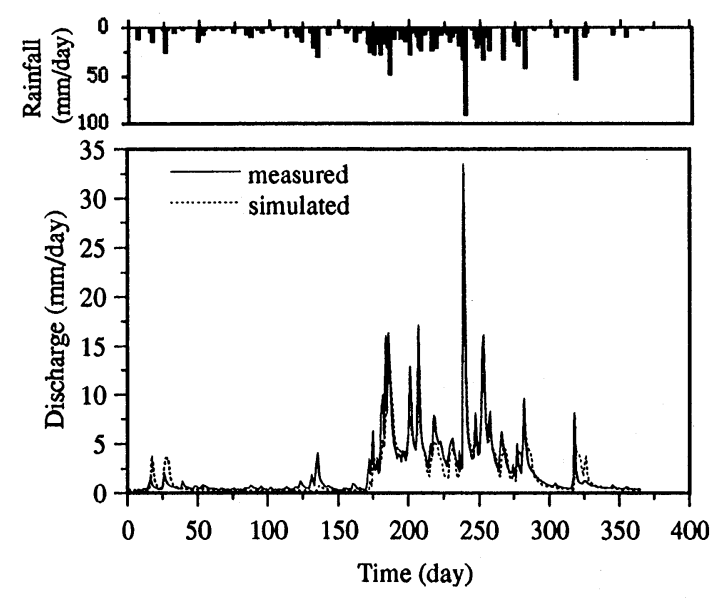

Fig. 8 Daily hydrographs at D-2 for case of flow interval length less than $600 \mathrm{~m}$ for year 1993

discharge data in the simulation period; $\bar{Q}_{0}$ is the mean value of the observed discharge.

From the results, it can be seen that there is no significant difference between the two simulation results. However, using of $600 \mathrm{~m}$ flow interval length saves $1 / 3$ of the computation time. This is useful for simulation in large catchments.

\section{(4) Effect of averaging of hillslope param- eters}

In the model, the hillslope parameters are averaged for each flow interval. If the catchment is too large, an error is introduced by the averaging procedure. In order to investigate the effects of averaging hillslope parameters, two simulations have been carried out. In the first case, the hillslope parameters (mainly hillslope length and hillslope angle in this study) are averaged

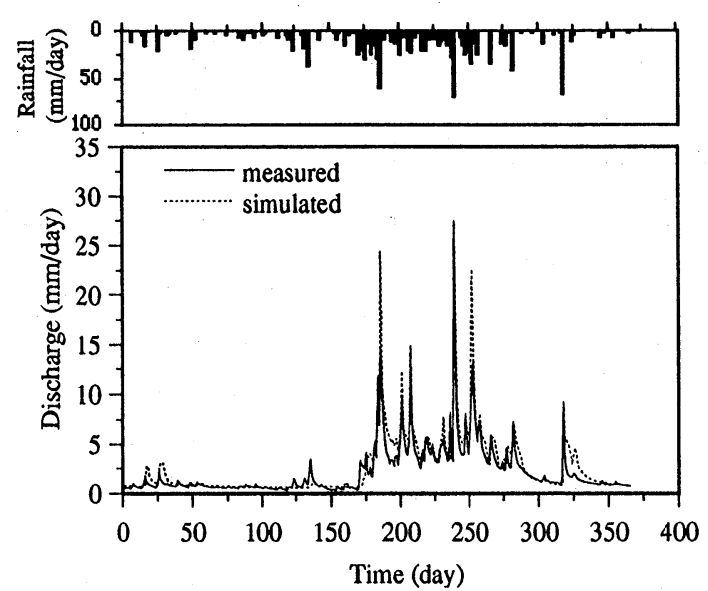

Fig. 9 Daily hydrographs at D for case of multiple sub-catchments and flow interval length less than $600 \mathrm{~m}$ for year 1993

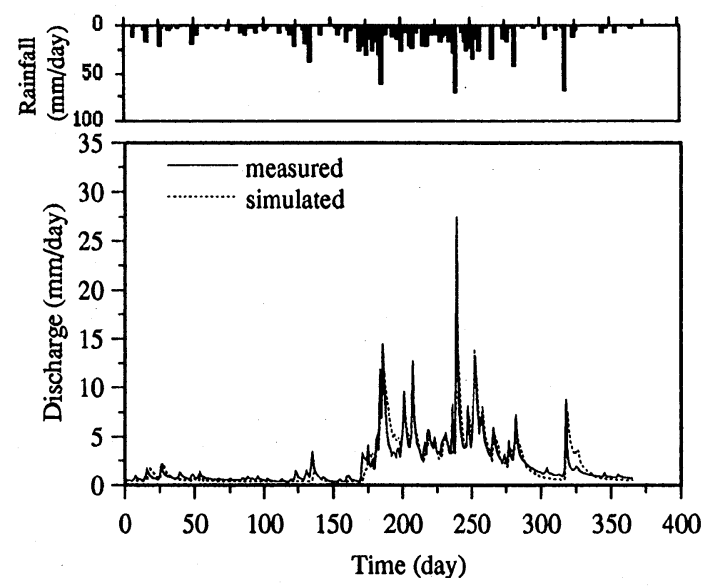

Fig. 10 Daily hydrographs at D for case of whole catchment and flow interval length less than $600 \mathrm{~m}$ for year 1993

in whole catchment for each flow interval. In the second simulation multiple sub-catchments (three sub-catchments, same as in the previous section) are considered. The hillslope parameters are averaged in each sub-catchment for the flow intervals of each sub-catchment. For both cases, the flow interval lengths are less than $600 \mathrm{~m}$. Fig.9 shows the comparisons of simulated daily hydrograph with the observed one at discharge-gauge D for the case of using multiple catchments. Fig.10 gives the result for the case of using single whole catchment.

Table 2 shows the simulation errors and computation CPU time for both simulations. From the results, we can see that the simulation errors for the two cases are very close. But the com- 
Table 1 Comparison of flow interval length effect

\begin{tabular}{|c|c|c|c|c|}
\hline Flow interval & \multicolumn{2}{|c|}{$\begin{array}{c}\text { less than } \\
600 \mathrm{~m}\end{array}$} & \multicolumn{2}{c|}{$\begin{array}{c}\text { less than } \\
300 \mathrm{~m}\end{array}$} \\
\hline Sub-catchment & $\mathrm{D}-1$ & $\mathrm{D}-2$ & $\mathrm{D}-1$ & $\mathrm{D}-2$ \\
\hline Error (\%) & 7.383 & 2.826 & 7.359 & 2.821 \\
\hline $\begin{array}{c}\text { Computation } \\
\text { time (s) }\end{array}$ & \multicolumn{2}{|c|}{110} & \multicolumn{2}{|c|}{144} \\
\hline
\end{tabular}

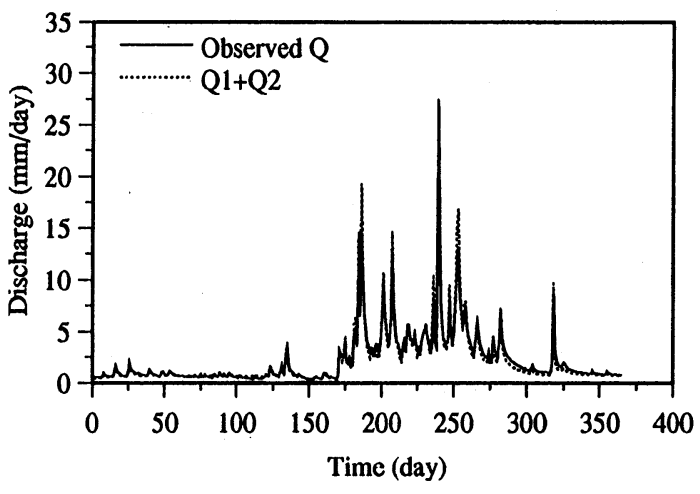

Fig. 11 Check of observed discharge at gauge D for year 1993

putation time for the case of simulating single whole catchment is only $1 / 3$ of simulating multiple catchments. In the two simulations, the hydraulic conductivities for groundwater and river interaction are not equal. Beauce the base flow of sub-catchment 1 (above gauge D-1) is higher than sub-catchment 2 (above gauge D-2) (Figs.7 and 8 ), the conductivity of groundwater used for sub-catchment 1 is higher than sub-catchment 2 in the case of multiple sub-catchments simulation. Value for sub-catchment 3 is considered as same as sub-catchment 2 . For the case of using single whole catchment, the conductivity of groundwater is taken as the average of the multiple subcatchments.

As seen from above results, the agreement of the simulated hydrograph with the observed one at gauge D-2 (Fig.8) is better than the others. The simulation error for gauge $\mathrm{D}$ is mainly from the simulating of sub-catchment 1 (above gauge D-1) according to the results. This can be seen by comparing the observed discharge data at gauge $\mathrm{D}$ by adding the discharges at gauge $\mathrm{D}-1$ and gauge D-2 (Fig.11). From Fig.11, it is found that the observed discharge at gauge $D$ is less than the sum of the observed discharges at gauges D-1 and D-2 in all of the peaks. That means there may be some error in the observed discharge data at D-1, most likely in the high flow component.
Table 2 Comparison of averaging hillslope parameters

\begin{tabular}{|c|c|c|}
\hline Simulation & $\begin{array}{c}\text { Single whole } \\
\text { catchment }\end{array}$ & $\begin{array}{c}\text { Multiple } \\
\text { sub-catchments }\end{array}$ \\
\hline Error (\%) & 3.185 & 4.744 \\
\hline $\begin{array}{c}\text { Computation } \\
\text { time (s) }\end{array}$ & 36 & 110 \\
\hline
\end{tabular}

\section{CONCLUSIONS}

As can be seen from the results shown above, the methodology gives good results for both whole catchment and sub-catchments simulations. It is seen that the geomorphologic area function provides an effective means for representing the catchment spatial heterogeneity. For the Karasu River, the two years simulation using multiple sub-catchments took about 2 min CPU time in Dec-Alpha $433 \mathrm{MHz}$ computer. In the case of single whole catchment simulation, only $33 \mathrm{sec}$ was needed for two years simulation. This model has the capability to simulate regional hydrological response for water resources planning and coupling with the regional atmospheric models.

In the present study we used only the spatial distributions of hillslope length, the slope angle and the rainfall. From the present study it was seen that flow interval length same as that of DEM resolution or twice the DEM resolution does not have much impact on the simulation results. The methodology can be extended to treat land cover, soil type and other parameter variations depending on the availability of data and the simulation needs.

\section{REFERENCES}

1) Yang, D., Herath S. and Musiake K.: Analysis of geomorphologic properties extracted from DEMs for hydrologic modeling, Annual Journal of $\mathrm{Hy}$ draulic Engineering, pp.105-110, 1997.

2) Naden P. S.: Spatial variability in flood estimation for large catchments: the exploitation of channel network structure, Hydrological Sciences Journal, Vol.37, pp.53-71, 1992.

3) Yang, D., Herath S. and Musiake K.: Simulation of catchment rainfall-runoff using area function and tank model, Proc. Annu. Conf. JSCE., Vol.52(II), pp.324-325, 1997.

4) Yang, D., Herath, S., Musiake, K. and Nakaegawa, T.: Development of a simplified physicallybased hillslope response model for modeling flood in mountainous catchments, Proc. Annu. Conf. Japan Soc. Hydrol. and Water Resour., pp.5758, 1997.

(Received September 30, 1997) 